\title{
OCH BUTTON TEST
}

\section{C.H. Kurita}

D-Zero Engineering Note: $3740.222-E N-88$

May 1, 1987

Rev A

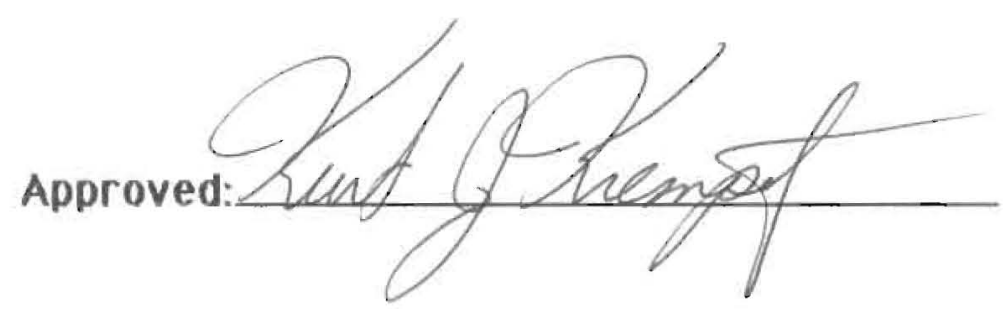




\section{INTRODUCTION}

A test was conducted to make a check on the yield stress of the copper spacer buttons to be used in $\mathrm{OCH}$. The tested button was made from copper no. 110, cold drawn rod, which has a documented yield stress value of 48,000 psi. The button was dimensioned as follows:
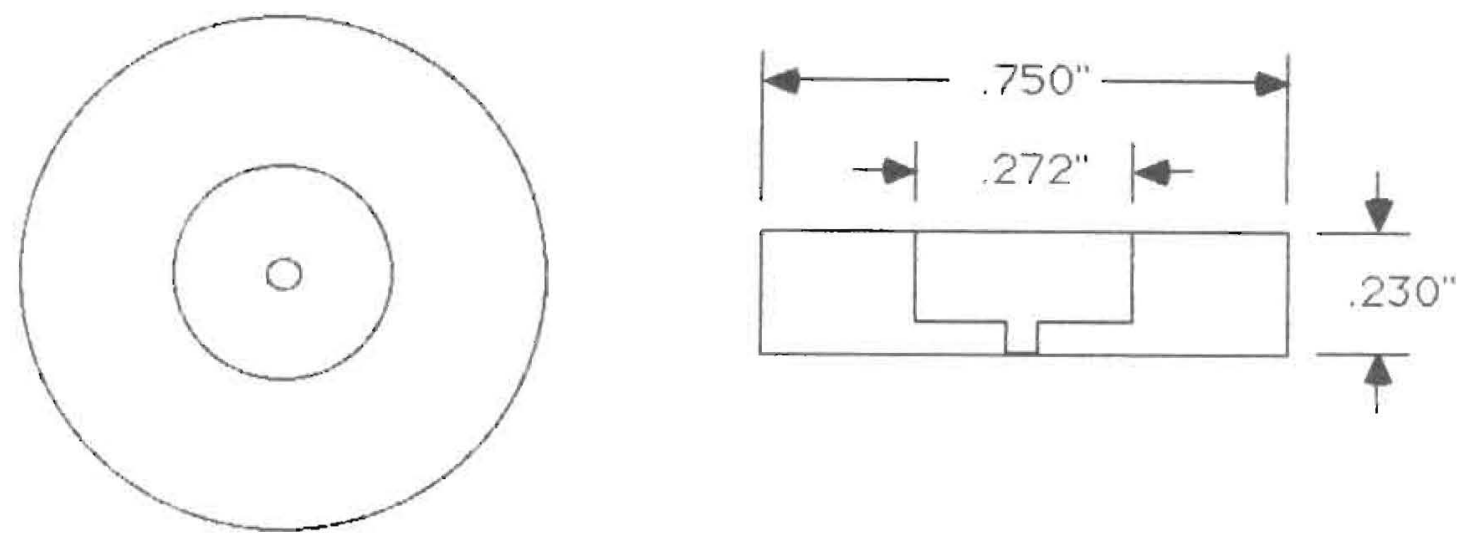

(not to scale)

\section{PROCEDURE}

The button was put into compression with the load applied to the face of the button. The resulting deflection vs. the applied cross load was then charted with the width of the chart having a $10,000 \mathrm{~kg}$ scale. While the chart speed was set at $1 \mathrm{~cm} / \mathrm{min}$, the cross head speed was set at .05 $\mathrm{cm} / \mathrm{min}$. To find a value of Young's Modulus for the $\mathrm{OCH}$ button, the compression test was run again with a chart width scale of $5,000 \mathrm{~kg}$. The chart speed was set at $10 \mathrm{~cm} / \mathrm{min}$ and the cross head speed at $.05 \mathrm{~cm} / \mathrm{min}$.

\section{RESULTS}

The curve generated on the chart was linear in nature until the button reached its yield point. Here, the slope of the curve began to change, increasing over a small area until a new linear curve was established. The point at which the slope changed would be considered the yielding point of the material, but here, there was no single distinct point. Instead there was a smooth transition between the two linear portions of the curve. In order to find where the yield point would occur, two lines were drawn, representing the best fit of each of the two slopes of the curve (before and after the yield point). The intersection of these lines was taken to be the point from which the yield stress could be calculated. See Chart 1. 
The point of intersection occurred $85 \%$ of the way along the $10,000 \mathrm{~kg}$ scale at a load of $8500 \mathrm{~kg}$. The yield stress was calculated using the formula:

$$
\begin{aligned}
& \Omega=F / A \\
& \Omega=y i e l d \text { stress } \\
& F=\text { applied load } \\
& A=\text { area being loaded }
\end{aligned}
$$

In this case:

$$
\begin{aligned}
& F=8500 \mathrm{~kg} \\
& A=(\pi / 4) *\left(d_{1}{ }^{2}-d_{2}{ }^{2}\right) \\
& A=(\pi / 4) *\left((.750 \mathrm{in})^{2}-(.272 \mathrm{in})^{2}\right) \\
& A=383 \mathrm{in}^{2} \\
& \Omega=\left(8500 \mathrm{~kg} / .383 \mathrm{in}^{2}\right) *(2.205 \mathrm{lbs} / \mathrm{kg}) \\
& \Omega=48,936 \mathrm{psi}
\end{aligned}
$$

To be sure that the calculated yield stress was in the right range of values, the test was repeated using a sample piece of stock copper with the dimensions.347" $\times .375^{\prime \prime} \times .376^{\prime \prime}$ and a loaded area of $.130125 \mathrm{in}^{2}$.

This plece required only $3,000 \mathrm{~kg}$ to yleld because of its reduced area. The calculated yield stress for this sample plece was 50,835 psi. This value was found to have less than a $4 \%$ deviation from the documented yield stress of the actual Copper no. 110 button. See Chart 2.

The curve generated in the modulus test was linear across the width of the $5000 \mathrm{~kg}$ scale chart except for a slightly curved portion appearing at the beginning of te loading. A portion of the straight linear curve (see chart 3) was used to calculate Young's Modulus using the following formula:

$$
\begin{gathered}
E=(F * L) /(\Delta L * A) \\
F=\text { applied load } \\
L=\text { length of button } \\
\Delta L=\text { change in length of button } \\
A=\text { area being loaded }
\end{gathered}
$$


In this case:

$$
\begin{aligned}
& \mathrm{L}=0.230 " \\
& \begin{aligned}
& \mathrm{A}=0.383 \mathrm{in}^{2}(\text { see above for calculation) } \\
& \mathrm{F} / \Delta \mathrm{L}=(2500 \mathrm{~kg})(\mathrm{min} / .05 \mathrm{~cm}) /(9.4 \mathrm{~cm})(\mathrm{min} / 10 \mathrm{~cm}) \\
&=53,191.5 \mathrm{~kg} / \mathrm{cm} \\
&=297,909.6 \mathrm{bs} / \mathrm{in}
\end{aligned} \\
& \mathrm{E}=(297,909.6 \mathrm{lbs} / \mathrm{in})(0.230 \mathrm{in}) /\left(0.383 \mathrm{in}^{2}\right) \\
& \mathrm{E}=1,309,124 \mathrm{psi}
\end{aligned}
$$

\section{CONCLUSION}

There was a $2 \%$ deviation between the calculated and documented values of the yield stress of Copper no. 110. The documented value was $48,000 \mathrm{psi}$, and the value obtained from this compression test was 48,936 psi. Using a factor of safety of 1.5, this calculated stress means that a load of 12,370 lbs can be safely applied to this structure. The calculated value of Young's Modulus for the copper button was smaller than the documented value of $17,000,000$ psi by a factor of 13. This discrepancy can probably be attributed to the hysteresis resulting from the large capacity of the machine used and the comparatively small size of the button tested. 


\section{CHART I}

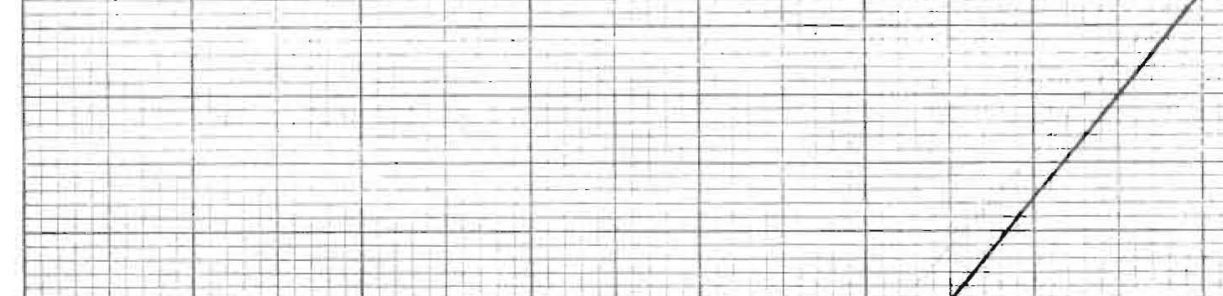


